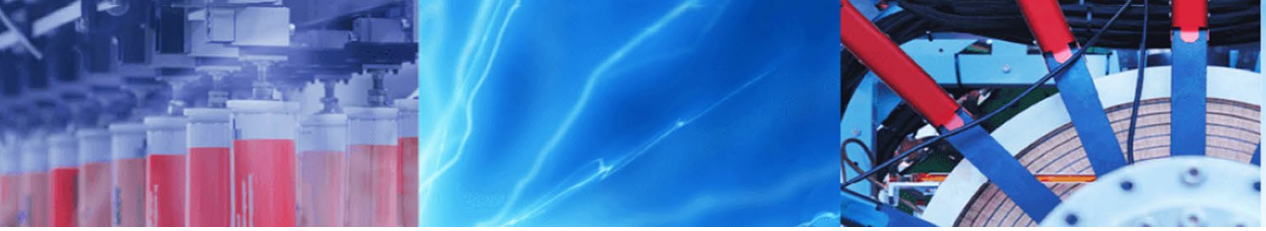

Research Article

\title{
Combine experimental and FEM analysis of adhesive bonded single lap joint with Al-alloy flat adherends and pre-embedded artificial defects
}

\author{
Prabhuprasad Sahu ${ }^{1} \cdot$ Prakash Chandra Mishra ${ }^{1,2}$
}

(c) Springer Nature Switzerland AG 2019

\begin{abstract}
Adhesive bonded lap joint is considered to be better substitute to riveted or welded joints for aerospace, marine and structural applications. It is due to the ability to develop relatively lower stress concentration and fatigue severity in highly dynamic environment. In real practice, there are defects present in the joint interface that decide the strength and durability of the component. Hence, it is required to understand the joint strength with different defect geometries. In this paper, a combined experimental and finite element method is conducted to evaluate the strength of lap joint of Al-alloy flat plate, pre-embedded with defects of various geometries: square, rectangle, circular and elliptical. The results of experimental and FEM analysis are converging, and indicate the clear variation of strength due to different type of defects. It encourages further analysis.
\end{abstract}

Keywords Adhesive bond · Lap joint · Von Mises stress · Strain · Deformation

\section{Introduction}

Now-a-days, adhesive bonded joints are applied to components used in various industries like automobile, aeronautical and other production industries. Reason being, it has the number of influential properties over the other traditional joints. Single lap joint is the simplest joining of two materials through an overlap arrangement of similar or dissimilar materials. It may be adhesively bonded, riveted or welded to form the joint. Among these, adhesively bonded joints are those joints in which adhesive are placed in the interface of strap and lap adherend. Such joints are suitable for small stress concentration in adherends, shows excellent fatigue properties, sealed against corrosion, relatively light weight and more efficient in load transfer $[1,2]$. Further, its manufacturing cost is very low and load is distributed over a large area. Again, joint efficiency is high (strength/weight ratio), no holes in the joint area to develop unnecessary stress concentration. It is better than riveted joint in aerodynamic applications. Above all, it can be retained in a high level of residual stress after initial cracking, if designed properly.

Further, there is difficulty in producing a defect free lap joint in real practice. But defect may be minimized to the lowest level by proper handling. The defect in a joint arises due to presence of voids, porosity and micro cracking in the lap area which causes a disbond and doesn't transfer load. As a result, stress increases at the other load transferring region but the micro level defect doesn't affect significantly to the joint strength. Heslehurst [3] worked on the anatomical response of an adhesive bond line defects and generalized the defects in adhesive bonded joints of debond/weak bond. He proposed that poor bonding affects the load transferring potential of the joint mainly due to the decrease in stiffness. The defects alter stress distribution and diminish the joint strength.

\footnotetext{
$\triangle$ Prakash Chandra Mishra, prabasmishra73@gmail.com | ${ }^{1}$ Green Engine Technology Center, School of Mechanical Engineering, KIIT University, Bhubaneswar 751024, India. ${ }^{2}$ Department of Mechanical Engineering, Veer Surendra Sai University of Technology, Burla, Sambalpur, Odisha 751024, India.
} 
With increasing demand of composite material application, carbon fiber gained popularity due to many improved properties. Moura et al. [4] worked with carbon epoxy single lap bonded joint with strip defect and studied it's strength using an adhesive of limited ductility. It is predicted that the joint strength is not affected due to presence of defect at the center of the overlap. While, presence of the same at the end reduces the joint strength significantly.

Karachalios and Adams [5] worked with high strength steel adherend. They estimated the joints up to overlap $25 \mathrm{~mm}$ on application of load fails due to global yielding, while that more than $25 \mathrm{~mm}$ overlap if loaded, gives rise to shear strain along the load plane interface. Grant and Adams [6] worked with toughened epoxy adhesive and mild steel adherend with bond line up to $3 \mathrm{~mm}$ thick. They found the increase in joint strength due to reduction in the bond line thickness resulted out of the bending moment at the end of the overlap.

Lang and Mallick [7] investigated the effect of adhesive spew geometry on stress fringe and the peak stresses of adhesively bonded single lap joint. The finite element technique is used in this case to evaluate the stresses for full triangular and full rounded spew. The $\tau_{x y} \sigma_{y y}$ and $\sigma_{x x}$ are reduced by $50 \%, 73 \%$ and $28 \%$ in case of triangular and $37 \%, 42 \%$, and $20 \%$ in case of rounded spew. Due to provision of a fillet to the full rounded spew, the $\sigma_{y y}$ and $\sigma_{\mathrm{xx}}$ is almost doubled. Circular arc (radius $=6 \mathrm{~mm}$ ) spew display the highest percent reduction in $\tau_{x y}, \sigma_{y y}$ and $\sigma_{x x}$ i.e. $60 \%, 87 \%$ and $35 \%$. So full triangular spew is advisable.

Neim et al. [8] worked on the effect of surface roughness on the joint strength and found that the mechanical interlocking between adherend and base drastically increases due to roughening of the surface in contact. In case of aluminum adherend used in a lap joint, due to the formation of disband [9] at the middle strength remains unaffected but the tensile loading is resisted by the end of the joint.

Karachalios and Adams [10] carried out combined numerical and experimental studies of low strength steel adherends in transferring load for total overlap. Due to longer overlap, failure is out of high local adhesive strains. Further to such studies, Ashrafi et al. [11] worked on lap joint of sinusoidal bonding surfaces and flat interface using fiber reinforced epoxy composite adherends. Mechanical behaviour and strength of bonded joints are greatly influenced due to non-flatness of interface. In some cases, its use is limited to thin adherends.

Tsuey et al. [12] studied the defect of lap joint in tension and its effect of shear strength using aluminum adherend and brittle adhesive. Bak et al. [13] worked on the effect of bonded lap thickness area on the tensile strength of lap and found that maximum stress occurred at the corner section of the joint whereas minimum stress occurred at the displacement $0.2 \mathrm{~mm}$. Significant decrease in the stress distribution occurs throughout the joint, due to enhanced adhesive thickness area of the overlap.

Xiaocong [14] studied the adhesively bonded single lap joint and found that due to loading, there occurs stress concentration near free ends of the interfaces, while there is almost zero stress at the center. Razavi et al. [15] worked on joint strength based on various substrate surface geometries. They correlated stress distribution in adhesive layer with the overall strength of the joint. Belingardi et al. [16] characterized adhesively bonded joint and suggested two harmful conditions; one due to offset of two adherends and subsequent bending moment and other variable stress distribution along adhesive layer resulted peak stress at ends.

The failure mode of joint changes from peel to shear due to tapering of adherends [17]. It is due to decrease in peel stresses in adhesive layer and subsequent increase in joint strength. The peak values of peel stresses at both ends of the bond line will be effectively reduced when using external tapers with $30^{\circ}$ fillets. Adams et al. [18] experimented on square ended joint without fillet and with fillet and found joint with $45^{\circ}$ fillets can bear around $5 \mathrm{kN}$ more load than without fillet and by making a comparison between $30^{\circ}$ and $45^{\circ}$ fillet found that $30^{\circ}$ fillet is better. Karachalios et al. [19] worked with three different adherends; Mild steel, Gauge steel, Hard steel and two adhesives; one is brittle and other is ductile in nature.

Banea et al. [20] described the adhesive bonding to be material joining process that involves melting and solidification bonding materials between adherends. Segerlind [21] gave out the same conclusion that as the lap length increases the stresses are in general reduced, but the stress maxima at the lap ends are increased.

Karachalios et al. [10] suggested the size of damage and location as dependable on parameters such as interface material plasticity, overlap length and loading type (Either tension and compression). Further adherend thickness and geometry of joint also influence the failure. Hunston et al. [22] predicted the nature of crack propagation in the brittle adhesive material in the joint. Further, Haghani et al. [23] made a parametric study on the effect of tapering length and the material properties of joint constituents on stress distribution in adhesive joints.

Grant et al. [24] worked on adhesively bonded lap joint and effect of temperature on it. They found that when the working temperature is more the joint becomes more ductile and load resistance capacity is less for which after applying a small amount of load to joint, it develops elongation. Brewis et al. [25] worked on adhesive bonded lap joint with aluminum alloy adherend and effect of moisture on it and found that the joint 
performance is better in dry condition than the higher humidity for this cause etched and anodized process is not preferable. Elhannani et al. $[26,27]$ made a probabilistic assessment of the defects present on the single lap bonded joints. Prior to this they also studied the effect of presence of number and shape of bonding defects on shear stress distribution on the joint.

From this broad literature review some gap can be observed which inspired for the present work. A lot of work has been done on adhesive bonded lap joint but little work has been focused on joints with defects. Although the joint strength under circular and rectangular defect has been investigated but aluminum alloy with such defects has not been experimented. The comparison of joint strength under different types of defect with different sizes has not been studied, which is the main goal of this research.

\section{Material and experimental methods}

The model deals with the joining of two Al-alloy plates with defects. The defects are created by giving Teflon coating in the center area of the joining surface. Araldite AW 106 resin/Hardener HV 953U epoxy adhesive is a multi-purpose, two components, room temperature curing, and viscous material of high strength and toughness that is suitable for bonding a variety of materials including metal, ceramic, wood, rubber glass, rigid plastic. The electrically insulating adhesive is easy to apply either manually by spatula and stiff brush or mechanically with meter/mix and coating equipment.

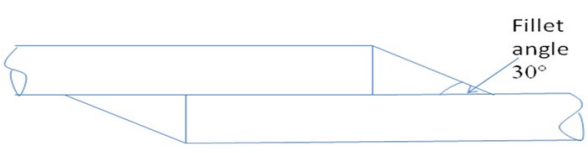

Fig. 1 Spew with Fillet angle (all dimensions in $\mathrm{mm}$ )

\subsection{Description of specimen}

The geometrical presentation of specimen shown in Fig. 1. The failure of longer overlap is more complex and dominated by shear strains [5]. Aluminum alloy yielded near loading edges incase of overlap $50 \mathrm{~mm}$ and more. $25 \mathrm{~mm}$ overlap fails due to global yielding [9]. So $25 \mathrm{~mm}$ overlap configuration was carried out in all tests. The dimension of tabs used in both ends of specimen kept constant that is $\left(25^{*} 25\right) \mathrm{mm}^{2}$ to reduce eccentricity of load path. Commonly used ASTM standard for testing lap joints is ASTM D1002-01, so the free length $\left(L_{f}\right)$ is taken as $63.5 \mathrm{~mm}$ and is constant for all specimens. A constant width of $25 \mathrm{~mm}$ and thickness of $3 \mathrm{~mm}$ adherend is used for all the specimens.

Thicker adherend induces more bending moment but it does not significantly reduce strength so $3 \mathrm{~mm}$ thickness of adherend is used. The lap joints were prepared immediately after mixing of resin and hardener with ratio $8: 10$ of thickness $0.1 \mathrm{~mm}$ because below a point around $0.3 \mathrm{~mm}$ of bond line thickness no significant changes in strength so it is decided that bond line thickness is $0.1 \mathrm{~mm}$ is suitable. Before applying adhesive on the adherend, it is required to increase roughness of applying area for better bonding. A $30^{\circ}$ angle of fillet is used in both sides of lap joint because peak values of peel stresses at both ends of the bond line will be effectively reduce while using external tapers with $30^{\circ}$ fillets as shown in Fig. 2. After preparing joint it should be left for $16-24 \mathrm{~h}$ to be cured under compression.

\subsection{Description of defects}

Experimental investigation is carried by considering four different types of defect, circular, rectangular, square, and elliptical. Only one constant dimension overlap area is used in all cases. Artificial defects are prepared with thin Teflon tap $(0.1 \mathrm{~mm})$ and placed at the middle of the overlap for which a disbond generates between lap and strap. It was found that the joint strength is not affected by the defect when the defect is located in the middle of the overlap. However when the defect is located at the ends of the overlap the defect decreases the joint strength.
Fig. 2 Geometrical view of single lap joint
(All Dimensions in mm)

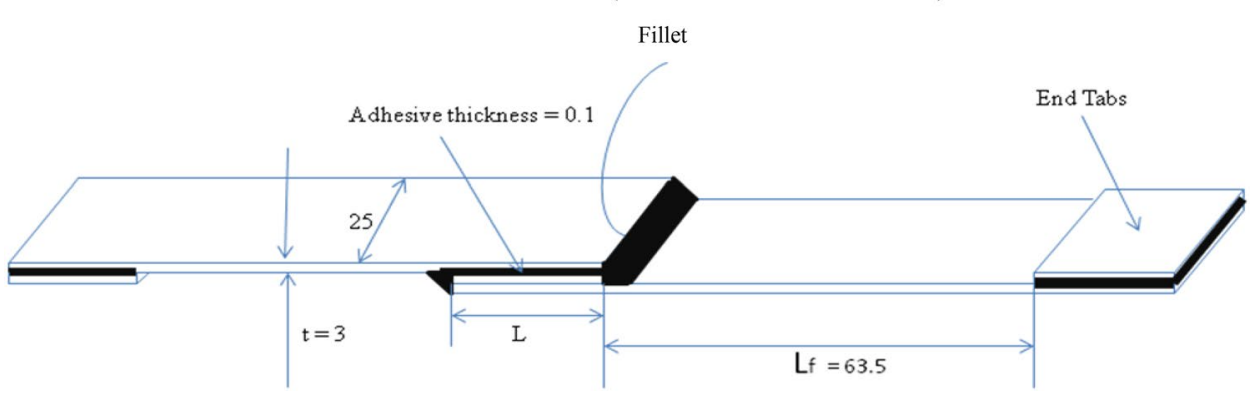


Fig. 3 Solid model of various defects; a square, $\mathbf{b}$ rectangular, c circular and $\mathbf{d}$ elleptic
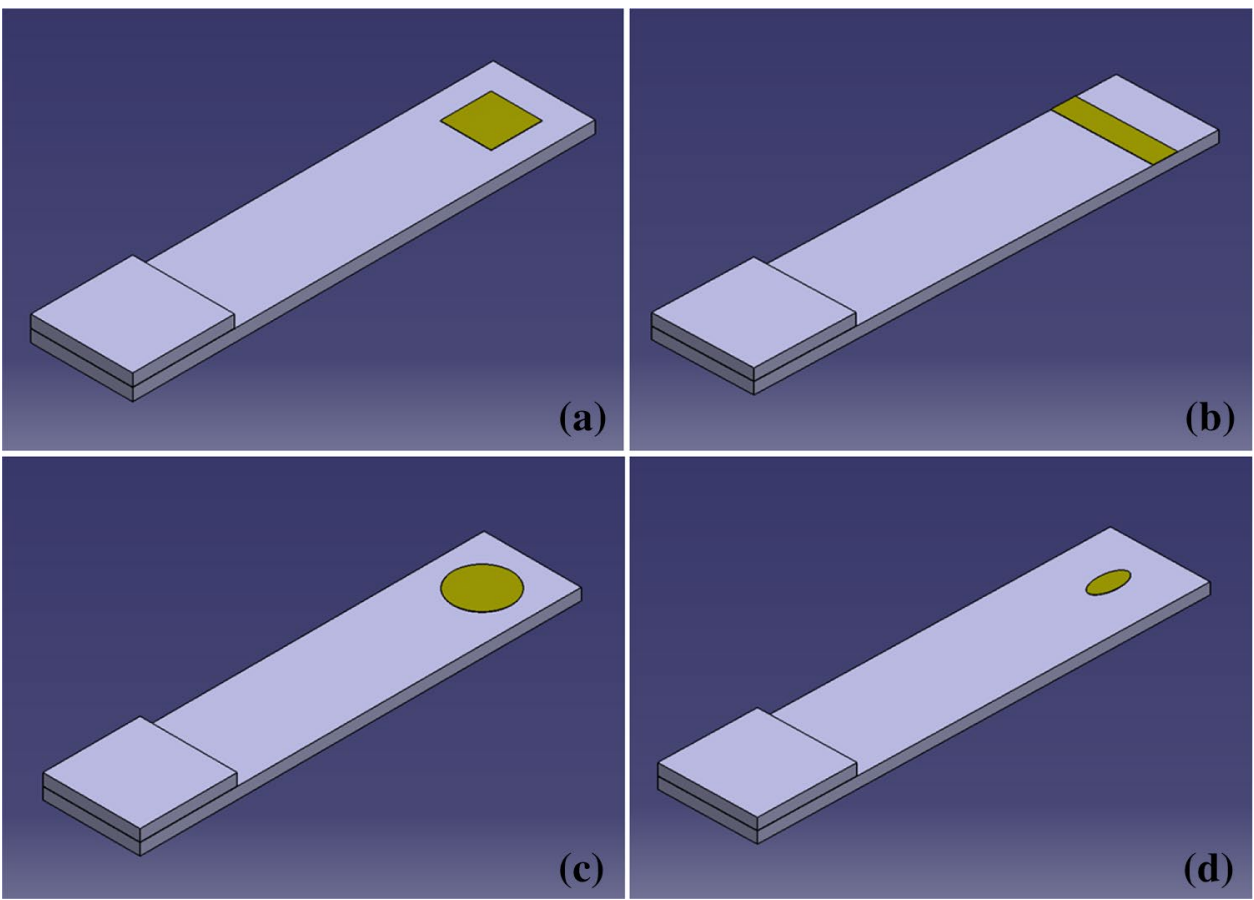

Table 1 Circular, rectangular and square defects and geometry

\begin{tabular}{llll}
\hline $\begin{array}{l}\text { Area of } \\
\text { defects } \\
\left(\mathrm{mm}^{2}\right)\end{array}$ & Circular (R in mm) & $\begin{array}{l}\text { Rectangular } \\
\left(\mathrm{a}^{*} \mathrm{~b} \text { in } \mathrm{mm}^{2}\right)\end{array}$ & Square (a in mm) \\
\hline 156 & $\mathrm{R}=7.04(\mathrm{C} 1)$ & $25^{*} 6.25(\mathrm{R} 1)$ & $12.49(\mathrm{~S} 1)$ \\
312 & $\mathrm{R}=9.965(\mathrm{C} 2)$ & $25^{*} 12.48(\mathrm{R} 2)$ & $17.66(\mathrm{~S} 2)$ \\
412 & $\mathrm{R}=11.5(\mathrm{C} 3)$ & $25^{*} 16.48(\mathrm{R} 3)$ & $20.297(\mathrm{~S} 3)$ \\
468 & $\mathrm{R}=12.2(\mathrm{C} 4)$ & $25^{*} 18.72(\mathrm{R} 4)$ & $21.63(\mathrm{~S} 4)$ \\
490 & $\mathrm{R}=12.48(\mathrm{C} 5)$ & $25^{*} 19.6(\mathrm{R} 5)$ & $22.13(\mathrm{~S} 5)$ \\
\hline
\end{tabular}

Rectangular size defects are placed covering whole width of the joint as shown in Fig. 3b. Elliptical defects are prepared (Fig. 3d) keeping a ratio between major axis (a) and minor axis (b). After maintaining ratio, all defects from $156 \mathrm{~mm}^{2}$ area are obtained, only four from $312 \mathrm{~mm}^{2}$ area and not a single one from 412,468 and 490 because any one of the axis exceeds overlap area. Table 1 shows the defect geometry of circular, rectangular and square shape, while Table 2 shows that of elliptical cases.
Figure 3a-d presents the joint defect solid model. The defects are placed on the middle of the joint. The corresponding specimens prepared with defects are given in the Fig. $4 a-d$.

\subsection{Testing method}

As per the ASTM D1002-01, the tests are conducted. At least five specimens are tested for each defect specimen. Wedge grips were used to fix the specimen and all tests are conducted keeping cross head speed constant while upper jaw is movable and lower jaw is fixed one representing a quasi-static process. Jaw separation speed is $5 \mathrm{~mm} /$ min. Tabs are used at the end of the specimen to maintain its eccentricity. Failure of the joint takes place in approximately 1-2 min depending on the defects. A pre failure sound generates for a time of 15-30 s and finally a high intense unusual sound generates which indicates the joint failure. All the tests were conducted at room temperature of approximately $25^{\circ} \mathrm{C}$ and at $50 \%$ relative humidity. Due to enhanced working temperature, joint becomes more

Table 2 Elliptical defects table

\begin{tabular}{|c|c|c|c|c|c|c|c|c|c|c|c|c|c|c|}
\hline \multirow[t]{3}{*}{ Defect size } & \multicolumn{14}{|l|}{$a / b$} \\
\hline & \multicolumn{2}{|c|}{$0.5(\mathrm{e} 1)$} & \multicolumn{2}{|c|}{$0.75(\mathrm{e} 2)$} & \multicolumn{2}{|c|}{$1(\mathrm{e} 3)$} & \multicolumn{2}{|c|}{$1.25(\mathrm{e} 4)$} & \multicolumn{2}{|c|}{ 1.5(e5) } & \multicolumn{2}{|c|}{ 1.75(e6) } & \multicolumn{2}{|c|}{$2(\mathrm{e} 6)$} \\
\hline & a & $\mathrm{b}$ & a & b & $a$ & $\mathrm{~b}$ & A & $b$ & a & $b$ & A & $b$ & $a$ & $\mathrm{~b}$ \\
\hline 156 & 4.9 & 9.9 & 6.1 & 8.13 & 7.0 & 7.0 & 7.8 & 6.3 & 8.6 & 5.7 & 9.3 & 5.3 & 9.9 & 4.9 \\
\hline 312 & - & - & 8.6 & 11.5 & 9.9 & 9.9 & 11.1 & 8.9 & 12.2 & 8.1 & - & - & - & - \\
\hline
\end{tabular}


Fig. 4 Specimen of various defects; a square, $\mathbf{b}$ rectangular, c circular and d elleptic
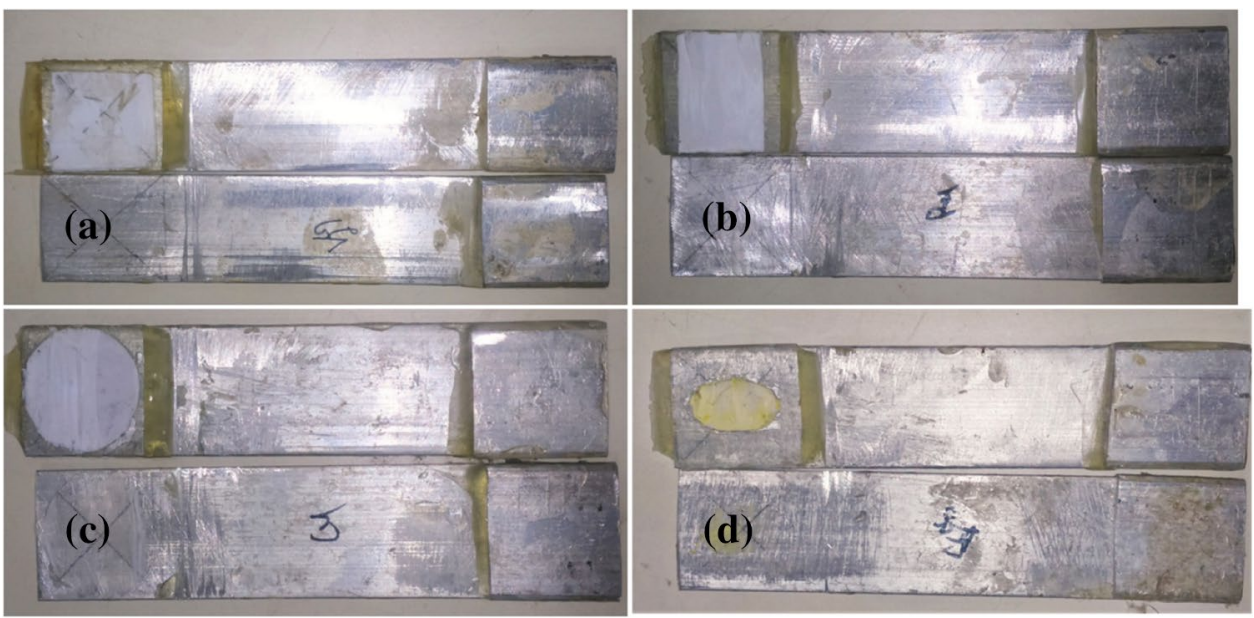

(a)

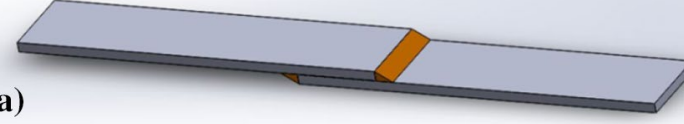

$L_{1}$

(b)

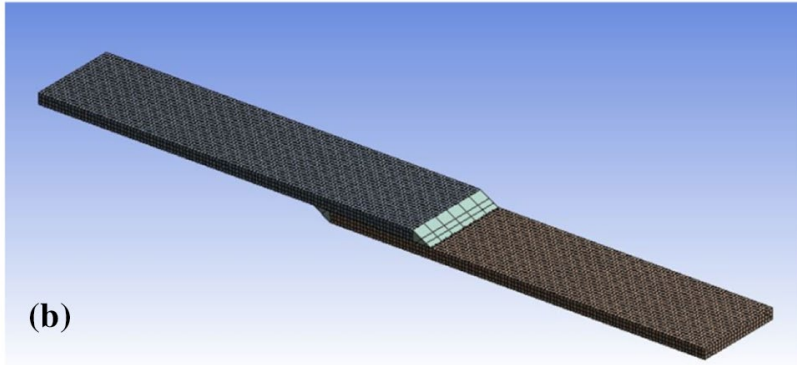

Fig. 5 Solid model and mesh model of lap joint

ductile which leads to reduced load carrying capacity. In contrast, reduction in temperature helps in better load carrying and less elongation. Further higher humidity reduces the strength and less humidity makes the joint brittle. Therefore the relative humidity of $50 \%$ is preferable.

\section{Finite element methods for defect joint strength}

For the defect joint creation, two flat plates of Al-alloy are joined through the solid model. The Fig. $5 \mathrm{a}$, b persents the solid model and the mesh model of the joint respectively. The material properties of all constituents such as adherends, epoxy are defined. Finite element technique is a most widely used study to evaluate stress, strain and deformations in component.

The solid model developed is meshed using in-built automatic mesh tool, which creates grid of suitable size for analysis. Table 3 shows the mesh details chosen for the analysis. The mesh convergence test is carried out to understand the accuracy of grid selection.

Table 4 shows the material properties of all the elements of the joint.

\section{Results and discussion}

\subsection{Experimental result analysis}

For square defect cases, all size of defects like $156 \mathrm{~mm}^{2}$, $312 \mathrm{~mm}^{2}, 412 \mathrm{~mm}^{2}, 468 \mathrm{~mm}^{2}$ and $490 \mathrm{~mm}^{2}$ were tested. Results are presented in Fig. 6. Then it was compared with joints without any artificial defect. There

Table 3 Mesh details

\begin{tabular}{llllll}
\hline Design of defect & No. of elements & No. of nodes & Transition ratio & Minimum edge length & Growth rate \\
\hline Square & 17,395 & 90,291 & 0.272 & $1 . e-001 \mathrm{~mm}$ & 1.2 \\
Rectangular & 17,388 & 90,227 & 0.272 & $1 . e-001 \mathrm{~mm}$ & 1.2 \\
Circular & 17,368 & 90,137 & 0.272 & $1 . e-001 \mathrm{~mm}$ & 1.2 \\
Elliptical & 17,360 & 90,001 & 0.272 & $1 . e-001 \mathrm{~mm}$ & 1.2 \\
\hline
\end{tabular}


Table 4 Material properties

\begin{tabular}{|c|c|c|}
\hline For plates & For defect & For binder \\
\hline Aluminium alloy & Teflon & Loctite \\
\hline Density $-2770 \mathrm{~kg} / \mathrm{m}^{3}$ & Density $-2160 \mathrm{~kg} / \mathrm{m}^{3}$ & Density $-1050 \mathrm{~kg} / \mathrm{m}^{3}$ \\
\hline Young's modulus-7.1E $+10 \mathrm{~Pa}$ & Young's modulus $-5 \mathrm{E}+08 \mathrm{~Pa}$ & Young's modulus-3000 MPa \\
\hline Poisson ratio- -0.33 & Poisson ratio- -0.46 & Poisson ratio- 0.4 \\
\hline Tensile yield strength $-2.8 \mathrm{E}+08 \mathrm{~Pa}$ & Tensile yield strength—3900 psi & Tensile yield strength-17 MPa \\
\hline Compressive yield strength $-2.8 \mathrm{E}+08 \mathrm{~Pa}$ & Compressive yield strength-3500 psi & Coefficient of thermal conduc- \\
\hline Coefficient of thermal conductivity $-2.3 \mathrm{E}-05 \mathrm{C}^{-1}$ & Coefficient of thermal conductivity $-7.5 \mathrm{~F}^{-1}$ & tivity-0/0001 $\mathrm{K}^{-1}$ \\
\hline
\end{tabular}

s1

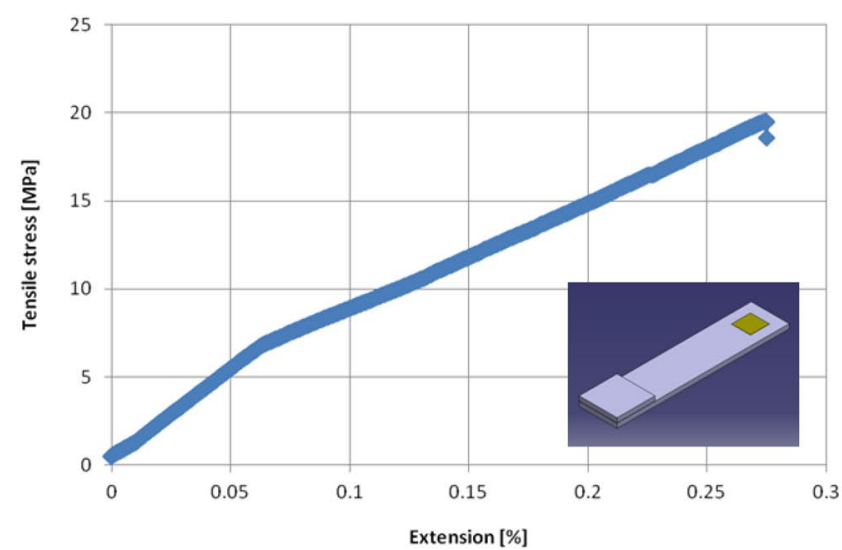

s3

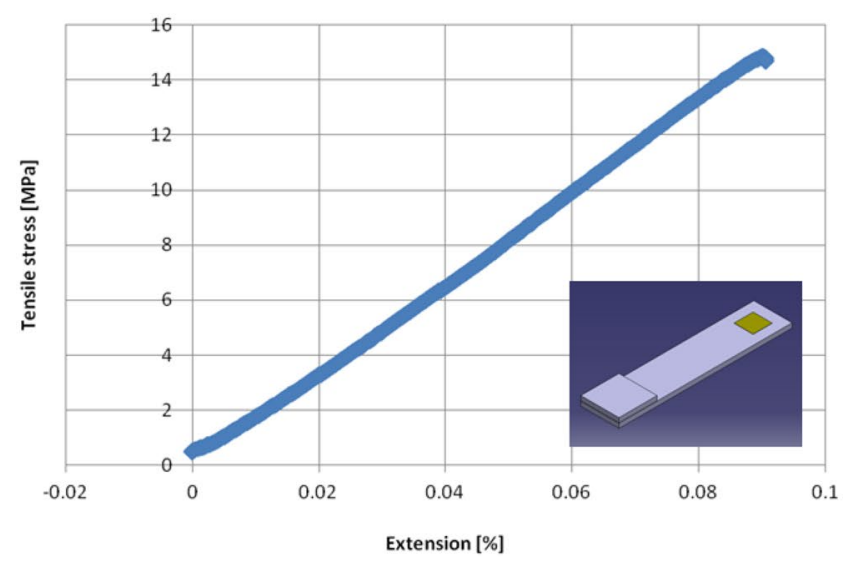

s2

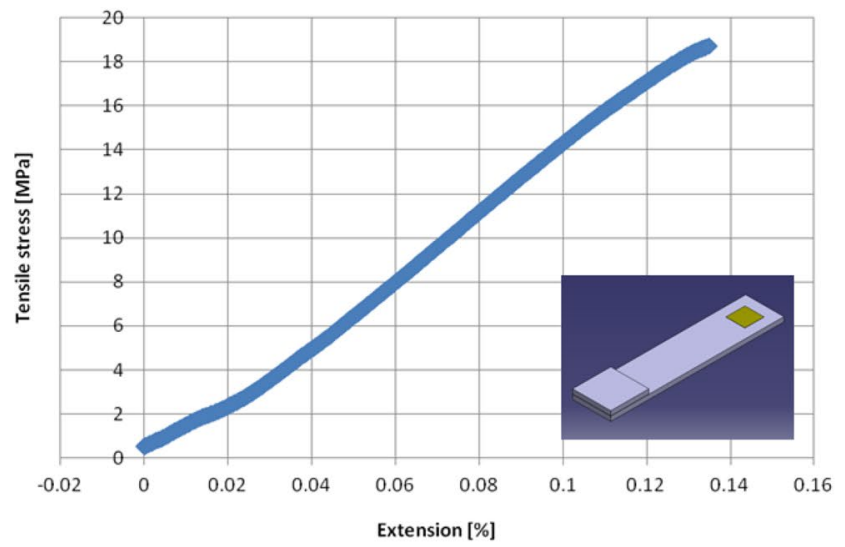

s4

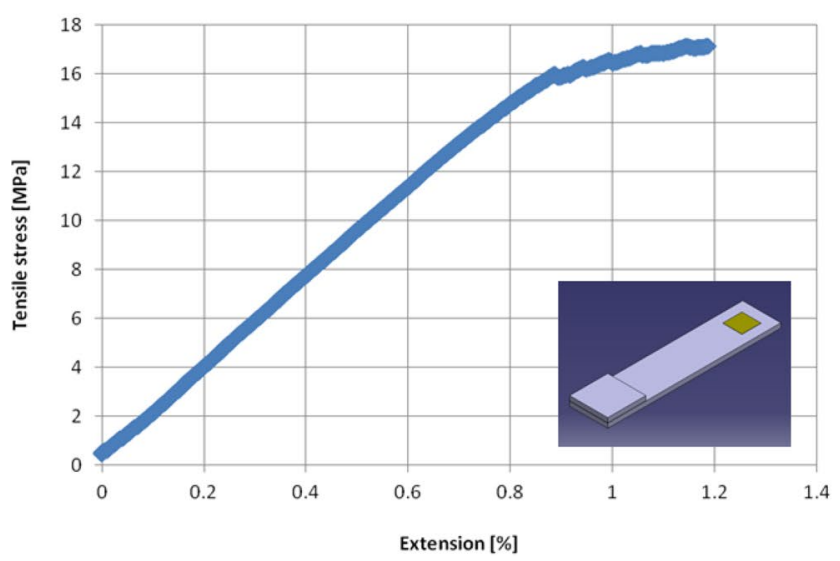

Fig. 6 Stress-strain relation for different size square defects

is a non-linear reduction in strength as the size of the defects increases. Result shows that presence of defect affects the strength of joint, whether it is a large defect or a small defect. It is further observed that defect size from 25 to $50 \%$ of overlap area doesn't affect to strength significantly, only extension decreases to an appreciate amount. When size of defect increases from 50 to $65 \%$, the strength also decreases to an appreciate amount and the extension of joint is very less. There is no difference in strength of joint when defect size increases from 65 to $75 \%$ only extension increases to a large extent.

When the defect size exceeds $75 \%$ of lap area then strength of joint reduces and the rigidity increases to a greater extent. The strength curve is similar with the rectangular defects but extension of the joint is unpredictable. There is not a single defect curve which exceeds elastic limits all fails before it. 
r1

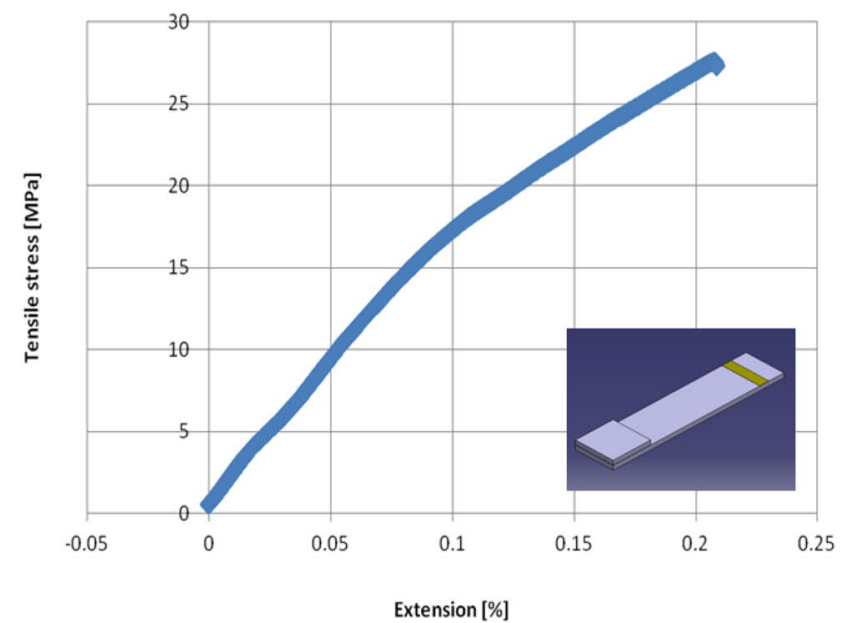

r3

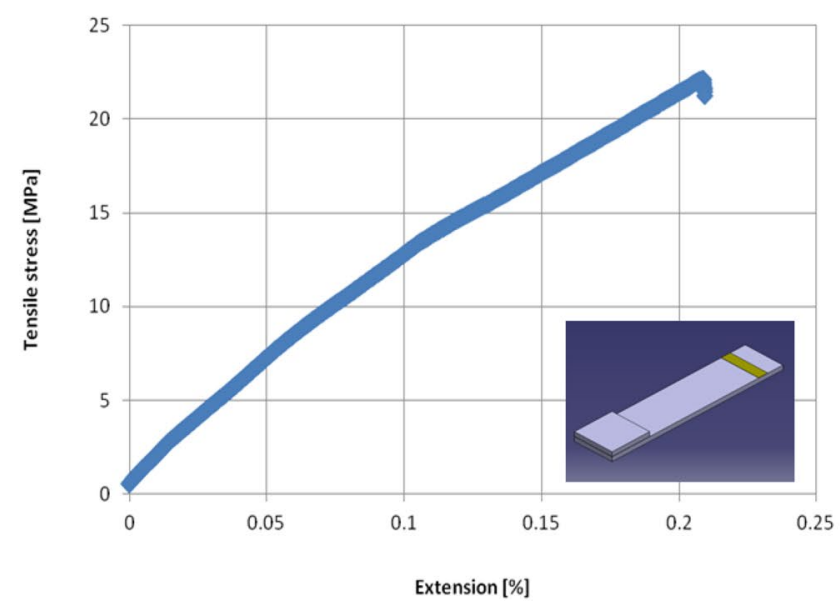

Fig. 7 Stress-strain relation for different size rectangular defects

For rectangular defect cases, all size of defects like $156 \mathrm{~mm}^{2}, 312 \mathrm{~mm}^{2}, 412 \mathrm{~mm}^{2}, 468 \mathrm{~mm}^{2}$ and $490 \mathrm{~mm}^{2}$ were tested. Results are presented in Fig. 7 and compared with joints without any artificial defect. There is a non-linear reduction in strength as the size of the defects increases. Result shows that presence of defect affects the strength of joint, whether it may be a large defect or a small defect. It is observed defect size from 25 to $50 \%$ of overlap area doesn't affect to strength significantly also not much differ in extension. When size of defect increases from 50 to $65 \%$, strength also decreases to an appreciate amount and extension of joint is same with $25 \%$. There is no difference in strength of joint when defect size increases from 65 to $75 \%$ only extension decreases. Further, when the defect size exceeds $75 \%$ of lap area then strength of joint reduces suddenly as well as the rigidity increases to a greater extent. Defect size from $65 \%$ to onwards the rigidity of the joint increases linearly. Focusing all curves of r2

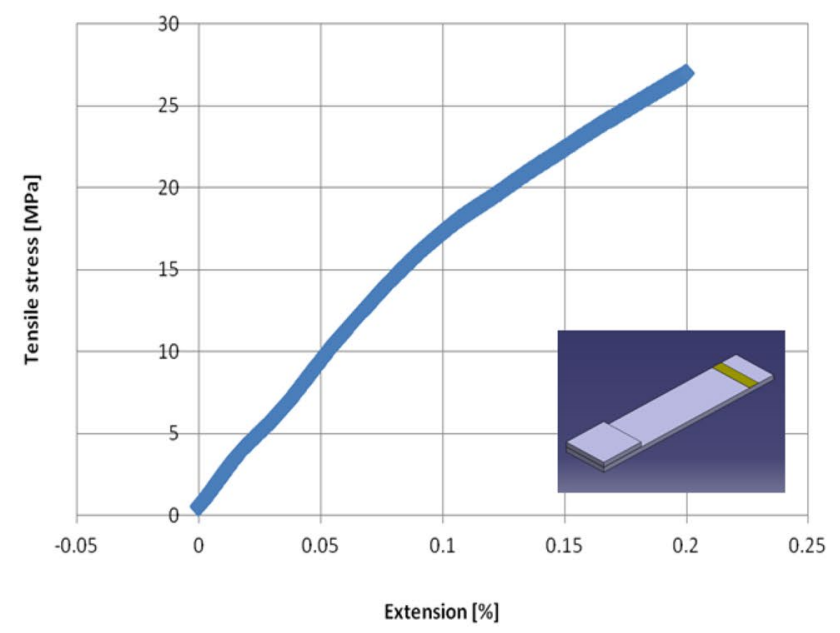

r4

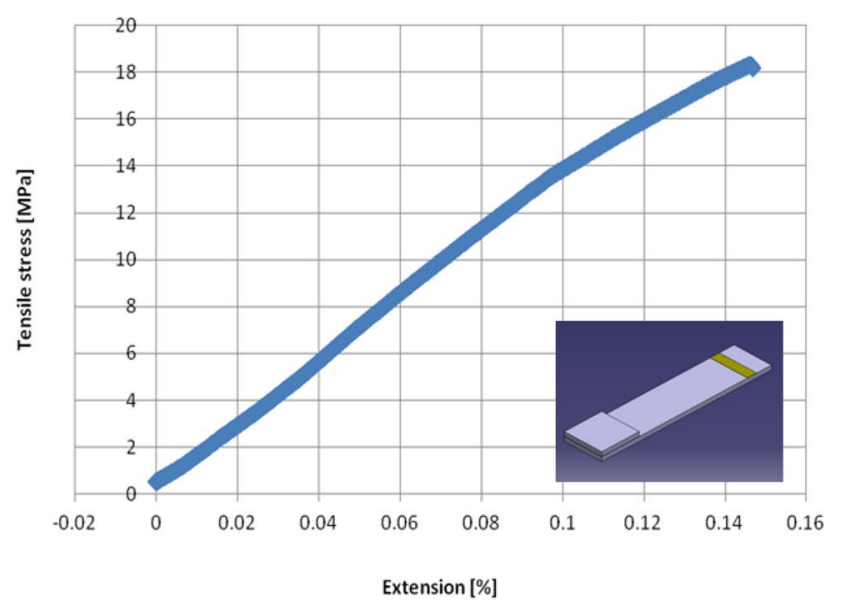

rectangular defects it is observed that $78 \%$ of overlap area defect achieves elastic limit. The failure of the joint starts as a small crack around the middle of the joint between adhrend and top fillet and that proceeds towards either side of joint then it proceeds downwards.

For circular defect case all size of defects like $156 \mathrm{~mm}^{2}$, $312 \mathrm{~mm}^{2}, 412 \mathrm{~mm}^{2}, 468 \mathrm{~mm}^{2}$ and $490 \mathrm{~mm}^{2}$ were tested. Results from tensile tests are presented in Fig. 8 and compared with joints without any artificial defect. There is a non-linear reduction in strength as the size of the defects increases. Result shows that presence of defect affects the strength of joint, whether it may be a large defect or a small defect. Whenever the defect size is $25 \%$, load carrying capacity is more but extension is less which means joint is somehow rigid. Defect size from 50 to $75 \%$ of overlap length, strength of joint is nearly equal only the difference is extension. Further, the defect size of $65 \%$ of overlap area gives highest extension. The strength of joint reduces 
c1

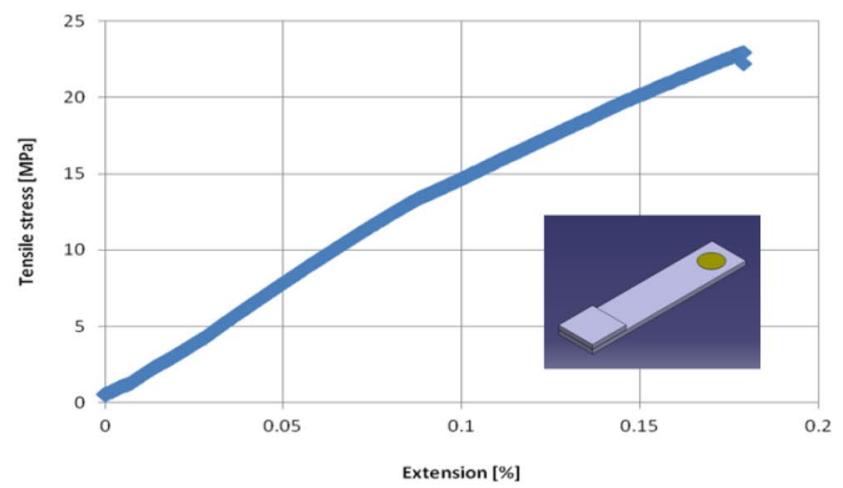

C3

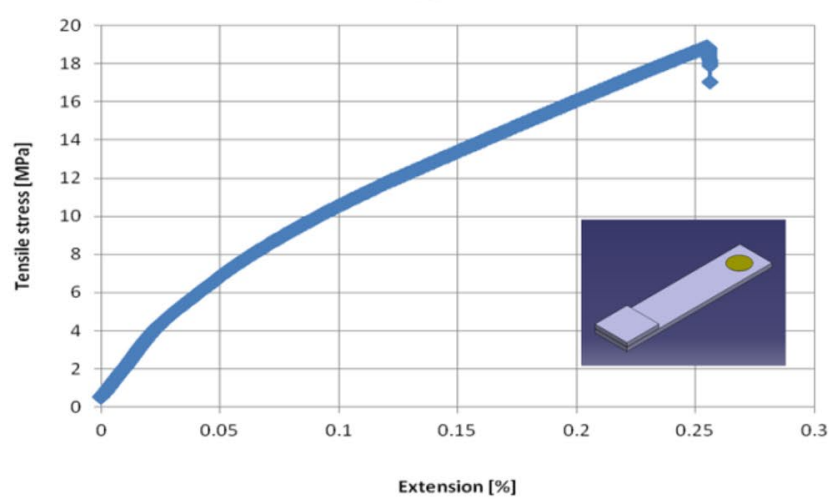

Fig. 8 Stress-strain relation for different size rectangular defects

with a great extent when the size of defect exceeds $75 \%$ of overlap area. The curve is completely different from other curves. Perhaps the joint is a failure one due to less contact area. It is also difficult to study because all curves start from $(0,0)$ coordinate and this curve starts from $(0,0.5)$ coordinate. Excluding c 5 curve focusing on rest four curves it is observed that $c 1, c 2, c 3$ fails before elastic limit while c4 can exceeds elastic limit. The failure of the joint starts as a small crack around the middle of the joint between adhrend and top fillet and that proceeds towards either side of joint then it proceeds downwards.

For the elliptical defect case, size of defects like $156 \mathrm{~mm}^{2}$ and $312 \mathrm{~mm}^{2}$ with considering different major and minor axis ratio was tested. In case of $412 \mathrm{~mm}^{2}$, $468 \mathrm{~mm}^{2}$ and $490 \mathrm{~mm}^{2}$, whole defect is not coming under the overlap region. After maintaining the ratio between major axis and minor axis defect area exceeds the limit of overlap. Results are presented in Fig. 9 and compared with joints without any artificial defect. Result shows that presence of defect affects the strength of joint, whether c2

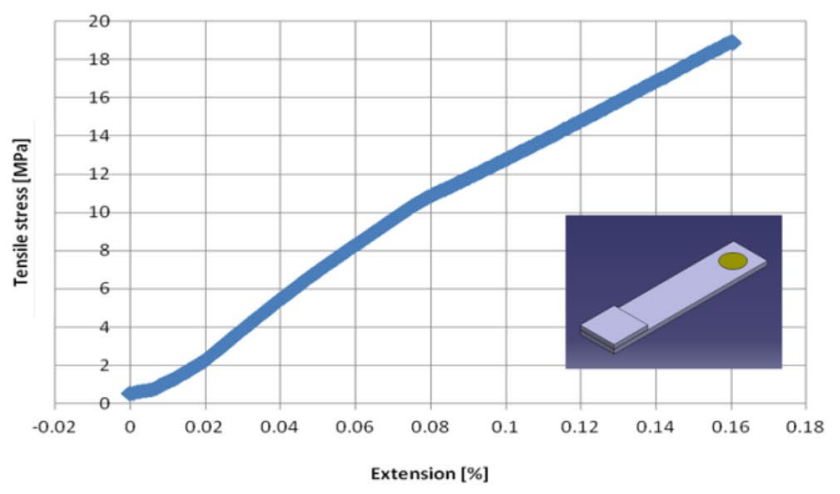

C4

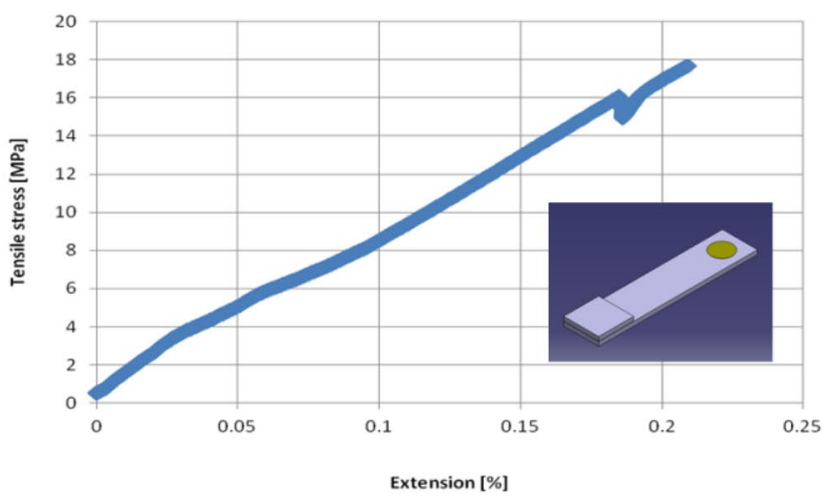

it may be a large defect or a small defect. Focusing all the stress strain curves of the elliptical defects, it was observed that no joint is crossing the elastic limit only e 11 curve has crossed the limit. All joints fail in a brittle manner. The failure of the joint starts as a small crack around the middle of the joint between adhrend and top fillet and that proceeds towards either side of joint then it proceeds downwards. When ' $a$ ' is smaller than 'b' joint can bear more load and by increasing length of $a$ and decreasing length of $b$ decreases load bearing capacity almost linearly but a contradiction occur when 'a' is equal to ' $b$ '. It gives less strength to the joint. In case of joints having defects like circular, rectangular and square seen joint strength decreases with increasing the size of defects, simultaneously strain varies from one defect to other but elliptical case is different from other because here area of contact is same still strength and strain of joint differs from one to other. Figure 10 presents the stress-extension curve for oversize defect $\left(s_{5}, r_{5}\right.$, $c_{5}$ and $e_{5}$ ) areas as given in the Tables 1 and 2 . 
e1

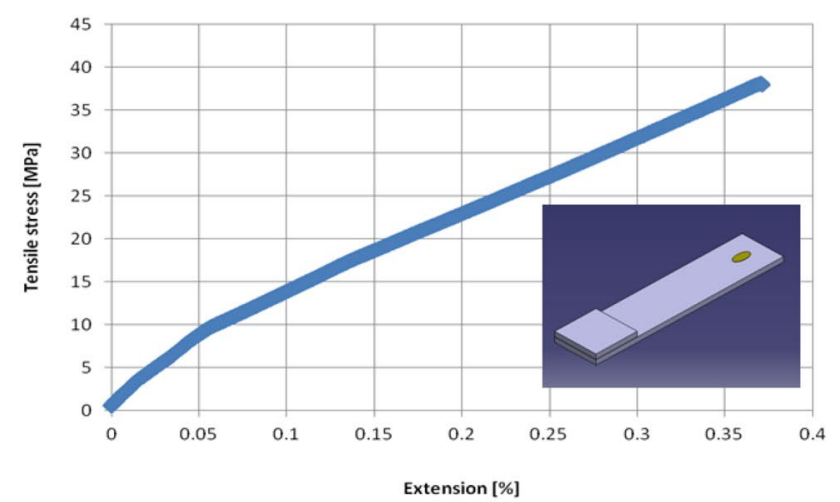

e3

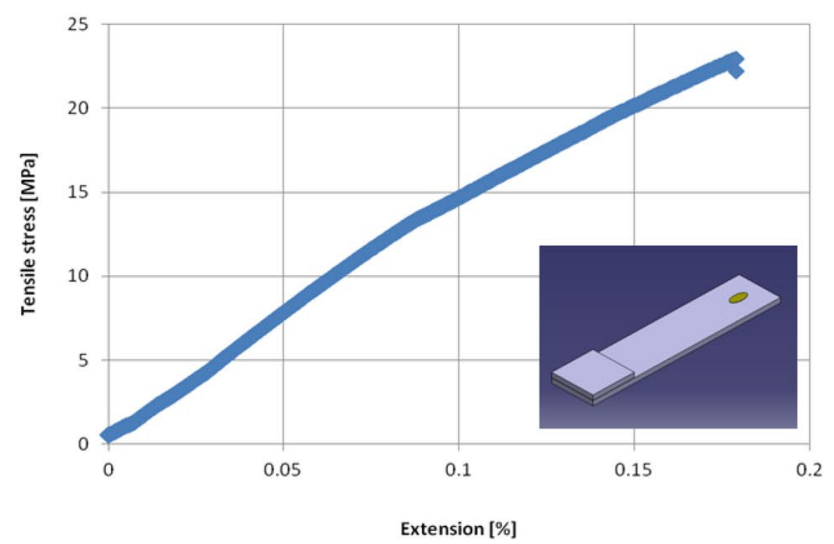

Fig. 9 Stress-strain relation for different size elliptic defects

Figures 11 and 12 represents the von Mises stress and the equivalent strain respectively. The maximum von Mises stress is in case elliptic defect geometry, while it is least for elliptic one. Similarly, the strain is more severe in case elliptic one. The maximum value of different parameters out of FEM model is presented in the Table 5.

The equivalent elastic stresses for the all specimens are compared to the stress in the simulation. In experiment it range of 18-23 MPa, while between 16 and $25 \mathrm{MPa}$ in the simulation, hence it is encouraging. Figure 13 shows the breaking load variation with respect to the defect size for different defect geometry. By comparing strength of all joints, it is found that rectangular defect with size of $156 \mathrm{~mm}^{2}$ gives maximum strength followed by elliptical defect of same size. Square defect with $156 \mathrm{~mm}^{2}$ gives less strength among all $156 \mathrm{~mm}^{2}$ defect sizes. For the e2

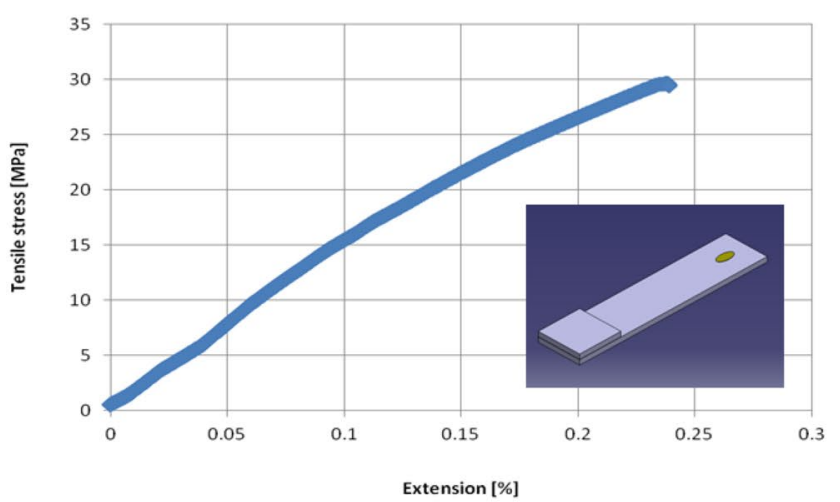

e4

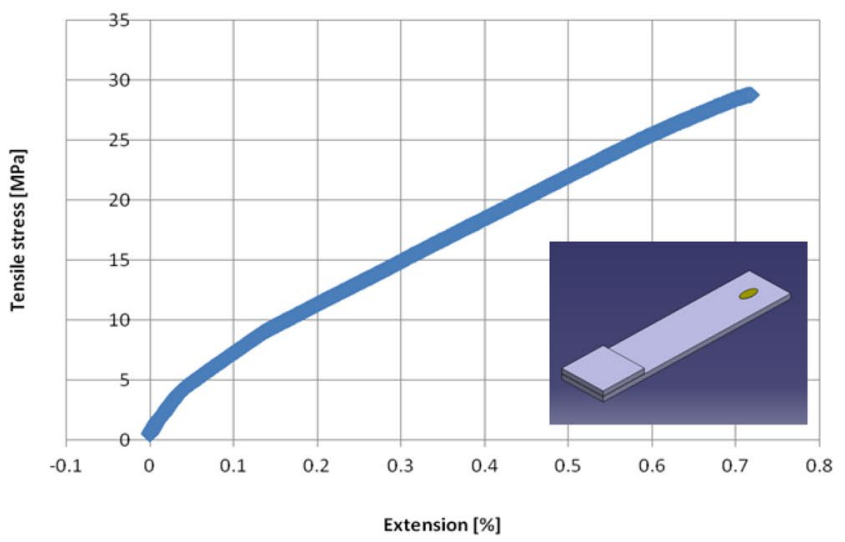

defect size of $312 \mathrm{~mm}^{2}$ again rectangular defect gives higher strength followed by circular defect. Some elliptical defects with size $312 \mathrm{~mm}^{2}$ give more strength than circular defect but while taking average of strength become lesser than circular defect. Large size defect area can't be embedded as elliptical area so excluding elliptical defect. Comparing three different size of defects best strength bearing capacity is by rectangular defect and followed by circular. When the defect size exceeds $75 \%$ of overlap area, strength reduces to a great extent and some cases it is observed that joint fails and unable to transfer load. 
s5

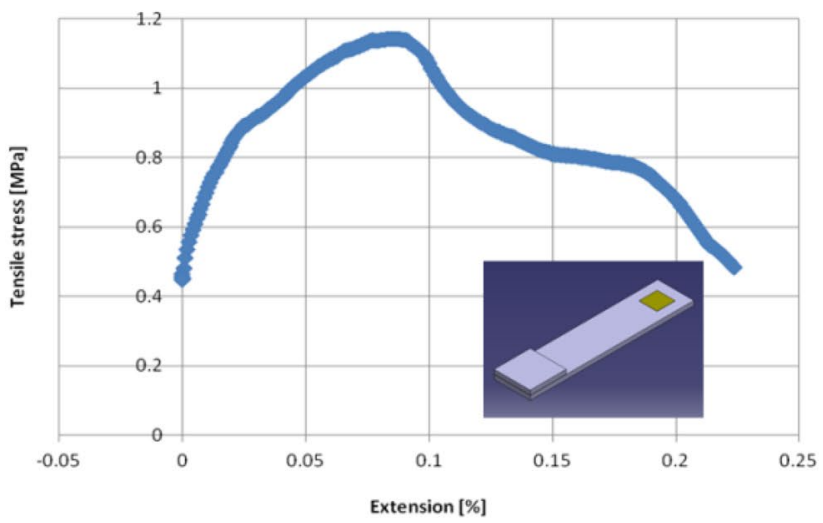

C5

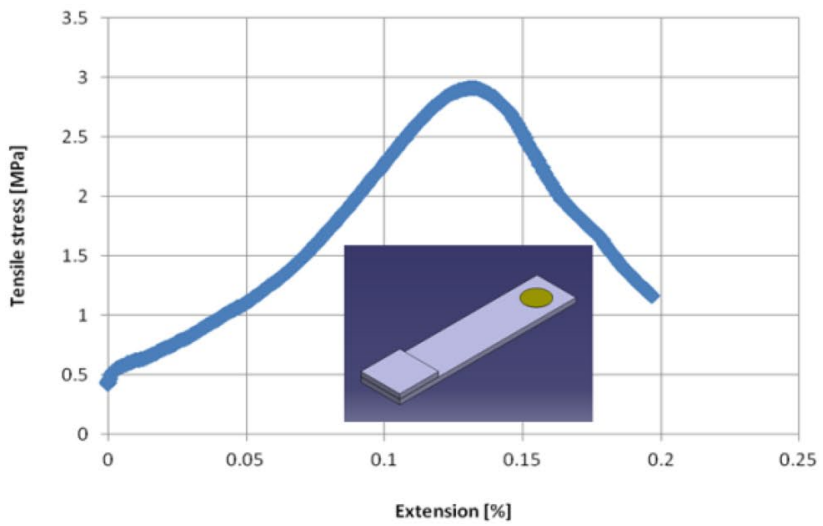

r5

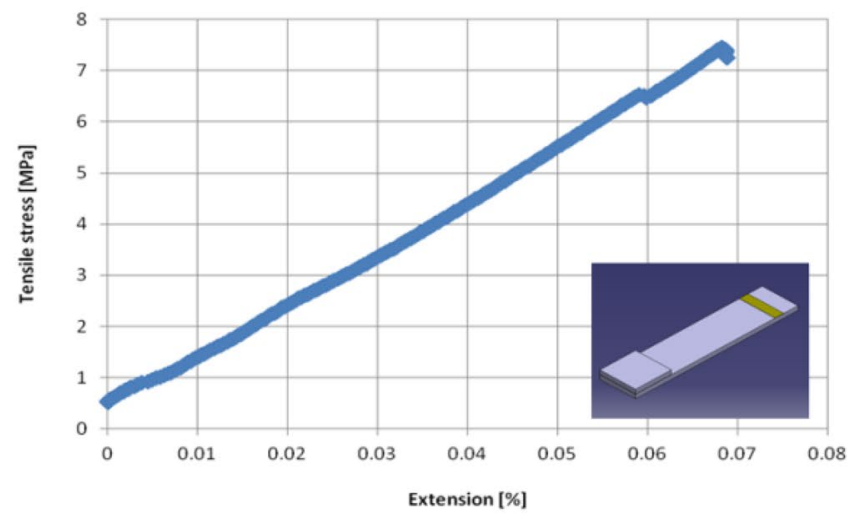

e5

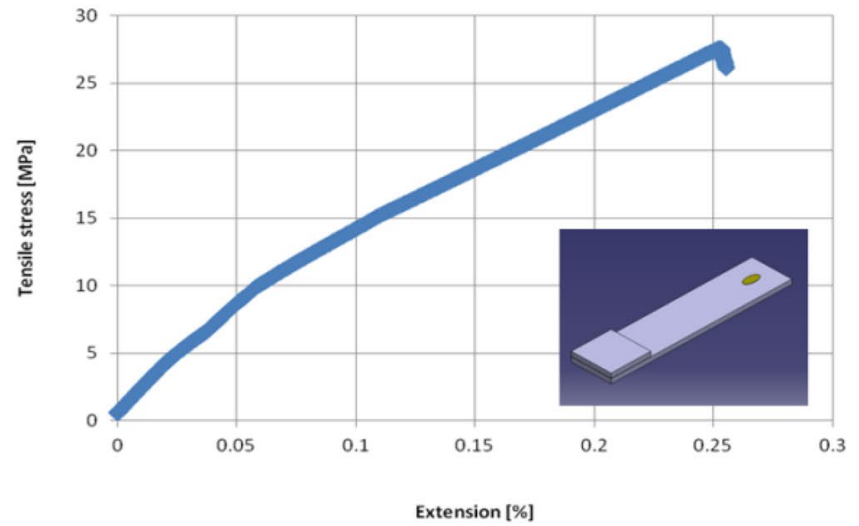

decreases apparently. It is due to less stress carrying area of joints. It is observed after a deliberate test that the defect size affect the joint strength.

- By observing rectangular, circular and square defect when the defect is middle part of overlap, affect joint strength less and defects nearer to fillet end of joint affect more to joint strength. If defect is nearer to fillet end and there is sufficient contact area from other sides it will not affect to joint strength up to a certain extent which is observed by comparing $25 \%$ and $50 \%$ of circular defect and $25 \%$ and $50 \%$ of elliptical defects joint respectively.

- When the defect spreads equally to each side of overlap area, it affects to strength greatly which is observed from circular and square defects joints. As the aluminum alloy used here has less strain and few 


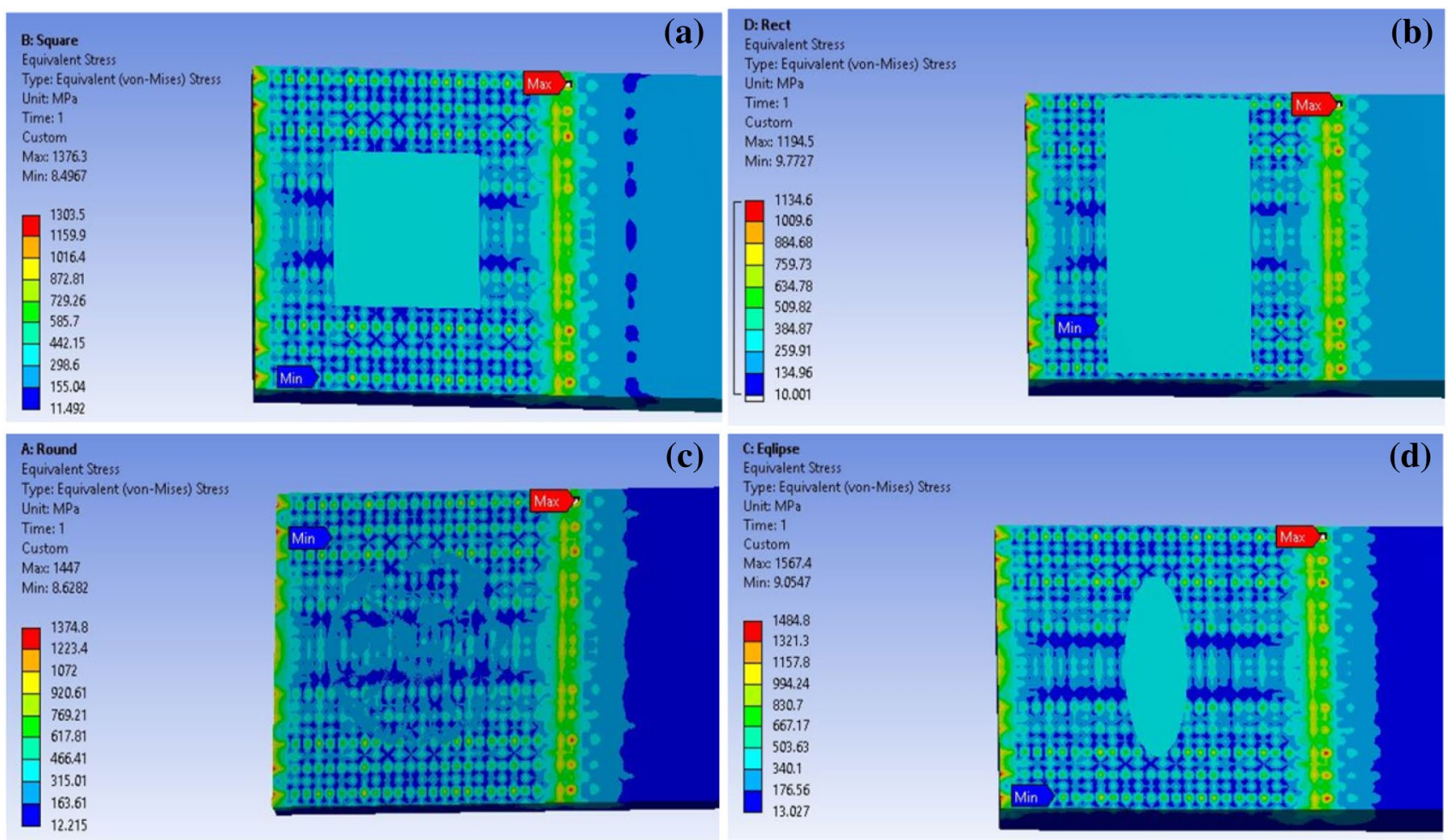

Fig. 11 von Mises stress distribution in the bonded region

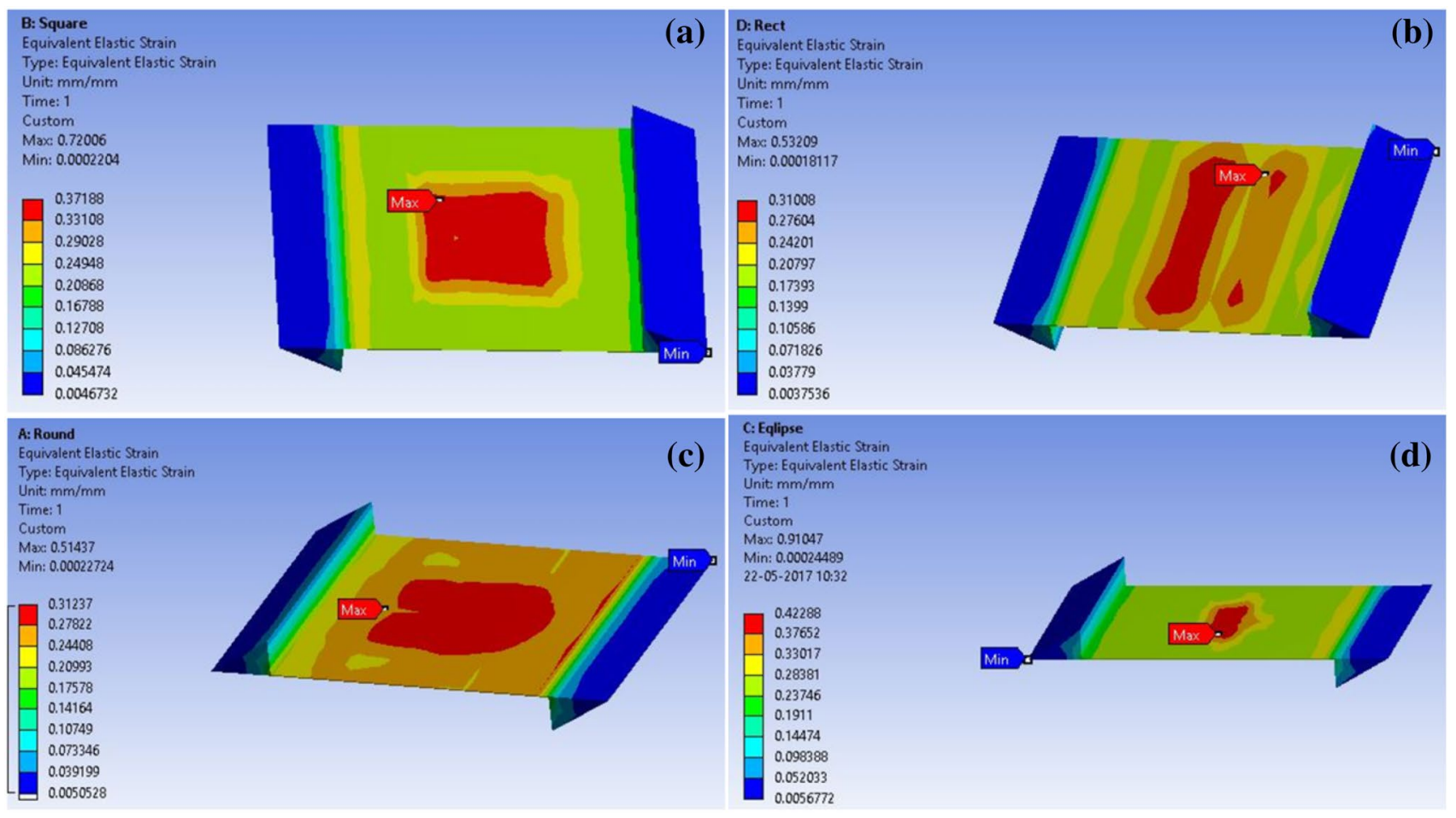

Fig. 12 Equivalent strain distribution in the bonded region 
Table 5 FEM outputs

\begin{tabular}{|c|c|c|c|c|c|c|}
\hline \multirow[t]{2}{*}{ Design of defect } & \multicolumn{2}{|c|}{ Stress (in MPa) } & \multicolumn{2}{|c|}{ Deformation (in mm) } & \multicolumn{2}{|c|}{ Strain $(\mathrm{mm} / \mathrm{mm})$} \\
\hline & Max stress & Min. stress & Max deform & Min. deform & Max. strain & Min. strain \\
\hline Square & 1376.3 & 11.274 & 152.04 & 0.28458 & 0.72006 & 0.0002204 \\
\hline Rectangular & 1194.5 & 9.786 & 131.58 & 0.1286 & 0.53209 & 0.00018117 \\
\hline Circular & 1447 & 12.069 & 160.36 & 0.10491 & 0.51437 & 0.00022734 \\
\hline Elliptical & 1567.4 & 13.027 & 173.64 & 0.097092 & 0.91047 & 0.0002513 \\
\hline
\end{tabular}

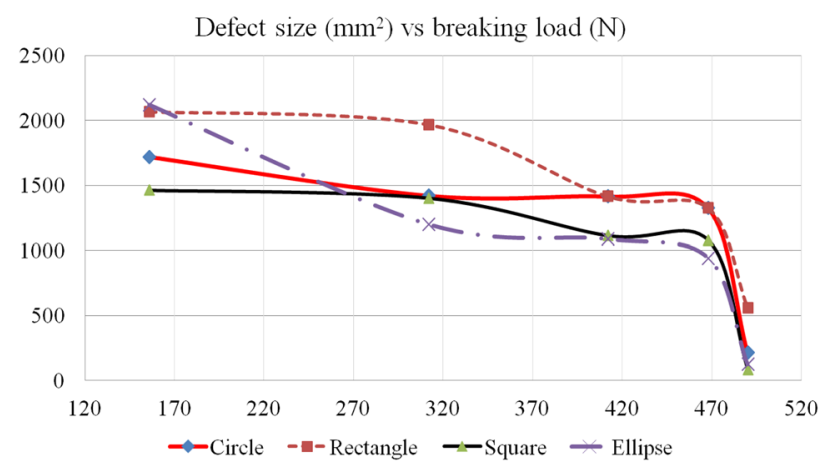

Fig. 13 Defect size and breaking load versus nominal bonded area

joints are less rigid so some case those joints may be the substitude of aluminum alloy material.

The limitation of this work is linear elastic numerical methods, which in real practice should be non-linear plastic models to match with the experimental findings. It is the future work for this approach. It can be extended further to the circular and non-flat plate using ductile adhesive under bending load conditions. The current work is limited to the defects at the center. However the future of this research can be extended to the arbitrary location of the defects and the comparative analysis can be made with the jonts without defects.

\section{Compliance with ethical standards}

Conflict of interest The authors declare that they have no conflict of interest.

\section{References}

1. Rodriguez RQ, de Paiva WP, Sollero P, Rodrigues MRB, de Albuquerque EL (2012) Failure criteria for adhesively bonded joints. Int J Adhes Adhes 37:26-36. https://doi.org/10.1186/s4056 3-016-0062-8

2. Segerlind LJ (1968) On the shear stress in bonded joints. J Appl Mech 35:177-178. https://doi.org/10.1115/1.3601142
3. Heslehurst RB (1999) Observations in the structural response of adhesive bondline defects. Int J Adhes Adhes 19:133-154. https ://doi.org/10.1016/S0143-7496(98)00029-3

4. de Moura MFSF, Daniaud R, Magalhaes AG (2006) Simulation of mechanical behaviour of composite bonded joints containing strip defects. Int J Adhes Adhes 26(6):464-473. https://doi. org/10.1016/j.ijadhadh.2005.06.010

5. Karachalios EF, Adams RD, da Silva LFM (2013) Single lap joint loaded in tension with high strength steel adherends. Int J Adhes Adhes 43:81-95. https://doi.org/10.1016/j.ijadh adh.2013.01.016

6. Grant LDR, Adams RD (2009) Experimental and numerical analysis of single lap joint for the automotive industry. Int J Adhes Adhes 29(4):405-413. https://doi.org/10.1016/j.ijadh adh.2008.09.001

7. Lang TP, Mallick PK (1998) Effect of spew geometry on stresses in single lap adhesive joints. Int J Adhes Adhes 18(3):167-177. https://doi.org/10.1016/S0143-7496(97)00056-0

8. Niem PIF, TI Lau, Kwan KM (1996) Effect of surface characteristics of polymeric materials on the strength of bonded joints. J Adhes Sci Technol 10(4):361-372. https://doi.org/10.1163/156856196X 00760

9. Suey T, Wang T, Ryan FW, Schonhorn H (1972) Effect of bonding defects on shear strength in tension of lap joints having brittle adhesives. J Appl Polym Sci 16:1901-1909. https://doi. org/10.1002/app.1972.070160804

10. Karachalios EF, Adams RD, da Silva LFM (2013) Single lap joints loaded in tension with ductile steel adherends. Int J Adhes Adhes 43:96-108. https://doi.org/10.1016/j.ijadh adh.2013.01.017

11. Ashrafi M, Ajdari A, Rahbar N, Papadopoulos J, Nayeb-Hashemi H, Vaziri A (2012) Int J Adhes Adhes 32:46-52. https://doi. org/10.1016/j.ijadhadh.2011.09.004

12. Schonhorn H, Ryan FW, Wang TT (1972) Effects of bonding defects on shear strength in tension of lap joints having brittle adhesives. J Appl Polym Sci 16:1901-1909. https://doi. org/10.1002/app.1972.070160804

13. Bak KM, Dinesh M, Kalaichelvan K (2012) Effect of adhesive thickness area of single lap joints in composite laminate using acoustic emission technique and FEA. Insight Non-Destruct Test Cond Monit 1-19

14. He Xiaocong (2013) Influence of boundary conditions on stress distributions in a single-lap adhesively bonded joint. Int J Adhes Adhes 53:34-43

15. Razavi SMJ, Esmaeili E, Samari M (2016) Stress analysis on a nonflat zigzag interface bonded joint. J Adhes 94(3):199-217. https ://doi.org/10.1080/00218464.2016.1257942

16. Belingardi G, Goglio L, Tarditi A (2002) Investigating the effect of spew and chamfer size on the stresses in metal/plastics adhesive joints. Int J Adhes Adhes 22:273-282. https://doi.org/10.1016/ S0143-7496(02)00004-0

17. Sarpe LH (1990) Adhesives and sealants, engineered materials handbook, vol 3. ASM International, Cleveland 
18. Adams RD, Comyn J, Wake WC (1997) Structural adhesive joints in engineering, 2nd edn. Springer. ISBN:978-0-412-70920-3

19. Karachalios EF, Adams RD (2013) Strength of single lap joints with artificial defects. Int J Adhes Adhes 45:69-76. https://doi. org/10.1016/j.ijadhadh.2013.04.009

20. Banea MD, da Silva LFM (2009) Adhesively bonded joints in composite materials: an overview. Proc IMechE L J Mater Des Appl 223(1):1-18. https://doi.org/10.1243/14644207JMDA219

21. Segerlind LJ (1968) On the shear stress in bonded joints. J Appl Mech 35(1):177-178. https://doi.org/10.1115/1.3601142

22. Hunston DL, Kinloch AJ, Wang SS (1989) Micromechanics of fracture in structural adhesive bonds. J Adhes 28(2-3):103-114. https://doi.org/10.1080/00218468908030877

23. Haghani R, AlEmrani M, Kliger R (2010) Stress distribution in adhesive joints with tapered laminates effect of tapering length and material properties. J Compos Mater 44(3):287-302. https ://doi.org/10.1177/0021998309345320

24. Grant LDR, Adams RD, da Silva LFM (2009) Effect of the temperature on the strength of adhesively bonded single lap and $T$ joints for the automotive industry. Int J Adhes Adhes 29:535-554. https://doi.org/10.1016/j.ijadhadh.2009.01.002
25. Brewis DM, Comyn J, Tegg JL (1980) The durability of some epoxide adhesive bonded joints on exposure to moist warm air. Int J Adhes Adhes 1(1):35-39. https://doi.org/10.1016/01437496(80)90032-9

26. Elhannani M, Madani K, Chama Z, Legrand E, Touzain S, Feaugas $X$ (2017) Influence of the presence of defects on the adhesive layer for the single-lap bonded joint-part II: probabilistic assessment of the critical state. Aerosp Sci Technol 63:372-386. https ://doi.org/10.1016/j.ast.2016.12.020

27. Elhannani M, Madani K, Legrand E, Touzain S, Feaugas X (2017) Numerical analysis of the effect of the presence, number and shape of bonding defects on the shears stresses distribution in an adhesive layer for the single-lap bonded joint; part 1. Aerosp Sci Technol 62:122-135. https://doi.org/10.1016/j. ast.2016.11.024

Publisher's Note Springer Nature remains neutral with regard to jurisdictional claims in published maps and institutional affiliations. 